\title{
Relationship between endoscopic mucosal healing and histologic inflammation during remission maintenance phase in ulcerative colitis: a retrospective study
}

\section{(ㄷ)(1) $(-)$}

Authors

Mimari Kanazawa ${ }^{1}$, Fumiaki Takahashi ${ }^{1}{ }^{12}$, Keiichi Tominaga ${ }^{1}$, Keiichiro Abe ${ }^{1}$, Naoya Izawa ${ }^{1}$, Koh Fukushi ${ }^{1}$, Kazunori Nagashima', Akira Kanamori ${ }^{1}$, Kazuhiro Takenaka', Takeshi Sugaya', Makoto lijima', Atsuko Takada ${ }^{3}$, Yasuo Imai $^{3}$, Hideyuki Hiraishi ${ }^{1}$, Atsushi Irisawa ${ }^{1}$

Institutions

1 Department of Gastroenterology, Dokkyo Medical University, Tochigi, Japan

2 Department of Internal Medicine, Japanese Red Cross Ashikaga Hospital, Tochigi, Japan

3 Department of Diagnostic Pathology, Dokkyo Medical University, Tochigi, Japan

submitted 30.8 .2018

accepted after revision 7.2.2019

Bibliography

DOI https://doi.org/10.1055/a-0869-7619 |

Endoscopy International Open 2019; 07: E568-E575

(c) Georg Thieme Verlag KG Stuttgart · New York

ISSN 2364-3722

Corresponding author

Keiichi Tominaga, MD, PhD, Department of

Gastroenterology, Dokkyo Medical University, 880,

Kitakobayashi, Mibu, Shimotsuga, Tochigi 321-0293, Japan

Fax: +81282867761

tominaga@dokkyomed.ac.jp

\section{ABSTRACT}

Background and study aims Recently, histological inflammation has been suggested to be an important predictor of sustained remission or relapse of ulcerative colitis (UC). In this study, we retrospectively compared severity of histological inflammation with endoscopic findings in UC patients with mucosal healing $(\mathrm{MH})$ in the remission maintenance phase, and investigated whether histological healing could be a predictor of sustained remission.

Patients and methods This study included 166 patients with $\mathrm{MH}$ in the remission maintenance phase. Endoscopic evaluation was based on the Mayo endoscopic subscore (MES), and MH was defined as MES 0 or 1 . Severity of histological inflammation was graded according to the Matts classification. Patients with Matts 1 and 2 were included in the histological healing $(\mathrm{HH})$ group, and those with Matts 3 , 4 , and 5 , in the non-histological healing $(\mathrm{NHH})$ group. In patients with $\mathrm{MH}$, incidence of relapse was compared and analyzed according to severity of histological inflammation.

Results The remission maintenance rate was significantly higher in the MES 0 group than in the MES 1 group ( $P=$ 0.004). The rate was significantly higher in the HH group than in the NHH group $(P=0.003)$. Within the MES 1 group, the rate was significantly higher in the $\mathrm{HH}$ subgroup than in the $\mathrm{NHH}$ subgroup $(P=0.030)$.

Conclusions This retrospective study suggests that histological healing can be a predictor of sustained remission in UC patients, and examination of histological inflammation provides useful information for long-term management of UC, particularly in patients with MES 1 .

\section{Introduction}

Ulcerative colitis (UC) is a chronic inflammatory bowel disease (IBD) with unknown etiology that is localized to the colonic mucosa. The disease manifests with symptoms such as abdominal pain, bloody stool, diarrhea, and weight loss and is characterized by repeated relapse and remission. As no curative treatments and strategies exist to date, a realistic treatment goal is to maintain remission for a long period after remission induction [1,2]. However, remission maintenance is often difficult. In recent years, achievement of mucosal healing $(\mathrm{MH})$ has been recognized as an important factor for remission maintenance [3-6] and shown to lower rates of relapse, hospitalization, and conversion to surgical treatment; reduce healthcare costs; and improve quality of life of patients [3-13]. Moreover, $\mathrm{MH}$ has also been reported to contribute to prevention of UC- 
associated colorectal cancer [14]. Thus, setting a treatment goal to achieve not only clinical remission but also $\mathrm{MH}$ is the current standard treatment of UC [3]. However, even among patients with $\mathrm{MH}$, a certain number of patients experience relapse. Various studies have been conducted on prediction of relapse. Recent studies have focused on histological inflammation as a superior indicator of sustained remission to $\mathrm{MH}$. Previous studies have shown that active histological inflammation is observed in approximately $40 \%$ of patients with $\mathrm{MH}[4,15-$ 18]. In recent years, the importance of histological healing has attracted attention as an indicator of sustained remission [19, 20]. However, no report of any study compared the severity of histological inflammation and endoscopic findings in patients remaining in remission for a long time.

In the current study, we retrospectively compared severity of histological inflammation with endoscopic findings in UC patients with $\mathrm{MH}$ in the remission maintenance phase, and investigated whether histological healing could be a predictor of sustained remission.

\section{Patients and methods}

\section{Study design and patient population}

This retrospective cohort study was conducted in two medical institutions and approved by the ethics committee of Dokkyo Medical University Hospital (approval no.29002). This study was conducted in accordance with the ethical principles associated with the Declaration of Helsinki and registered in the University Hospital Medical Network Clinical Trials Registry [UMIN000033452]. We provided a means to opt out instead of omitting informed consent, which is a way to guarantee the opportunity for research subjects to notify and publish research information on our website.

The primary endpoint of this study was to examine whether histological healing could be a predictor of sustained remission in UC patients with $\mathrm{MH}$. The second endpoint was to investigate risk factors for relapse (age, sex, affected area, disease duration, smoking rate, and duration of remission before entry). In considering duration of remission before entry, patients were divided into two groups, one maintaining remission for 1 year before entry and one maintaining remission over 1 year (longer term).

To select eligible patients, we retrospectively reviewed medical records of 555 UC patients aged 12 to 86 who had been treated at Dokkyo Medical University Hospital and Japanese Red Cross Ashikaga Hospital between January 2008 and March 2016. Of 207 patients who had remained in clinical remission with only 5-aminosalicylic acid (ASA) for at least 1 year without dose modification, who had been found to have MH by colonoscopy, and who had undergone a biopsy, 166 were confirmed to have consumed $80 \%$ of prescribed medications based on their medical records and included in the current study ( $>$ Fig.1). The ASA preparations used were a time-dependent ASA preparation (Pentasa, $2000-4000$ mg/d; Kyorin Pharmaceutical Co., Ltd., Tokyo, Japan), a pH-dependent ASA preparation (Asacol, 2400 - 3600 mg/d; Zeria Pharmaceutical Co., Ltd., Tokyo, Ja-

\section{5 patients}

Exclusion patients

- Remission maintenance duration of less than 1 year

- Using immuno-modular or biologic therapy

- Mayo endoscopic subscore 2 and 3

- Biopsy is not performed at endoscopy

\section{7 patients}

Exclusion patients

- Oral administration adherence is less than $80 \%$

166 patients

- Fig. 1 Patient inclusion and exclusion criteria.

pan), and salazosulfapyridine (Salazopyrin, 2000 - $4000 \mathrm{mg} / \mathrm{d}$; Pfizer Japan Inc., Tokyo, Japan), which are approved in Japan.

Meanwhile, patients who had been treated with immunomodulators or anti-tumor necrosis factor- $\alpha$ drugs were excluded. Clinical remission was defined as Rachmilewitz Clinical Activity Index of 4 points or lower [21]. The strategy for treatment was on the basis of the Japanese clinical guideline for UC [22]. Therefore, clinical evaluation and follow-up for UC patients were the same way in the two institutions.

\section{Endoscopic evaluation}

According to the Montreal Classification of UC, the colon was divided into the following three segments [23, 24]:

1. Ulcerative proctitis (E1) (Proctitis type): involvement limited to the rectum (ie, proximal extent of inflammation is distal to the rectosigmoid junction).

2. Left-Sided UC (E2) (Left-sided type): involvement limited to the portion of the colorectum distal to the splenic flexure.

3. Extensive UC (E3) (Pancolitis type): involvement extends proximal to the splenic flexure.

Endoscopic evaluation was based on the Mayo endoscopic subscore (MES) [25, 26], where MES 0 (no friability, granularity, and intact vascular pattern) corresponds to normal mucosa and MES 1 (mild erythema or decreased vascular pattern) corresponds to healed mucosa. $\mathrm{MH}$ was defined as a state of normal and healed mucosa. In addition, MES 2 (marked erythema, absent vascular pattern, friability, and erosions) and MES 3 (spontaneous bleeding and ulceration) were regarded to correspond to mucosa in the active phase ( $\triangleright$ Fig.2). Endoscopic findings obtained after at least 1 year of clinical remission were evaluated by two endoscopists, each one selected at the two medical institutions from those with 10 years or more experience with a specialty in IBD who annually treated 200 or more patients with IBD. Endoscopic findings on which the two endoscopists agreed were included in analyses. When they disagreed on evaluation 

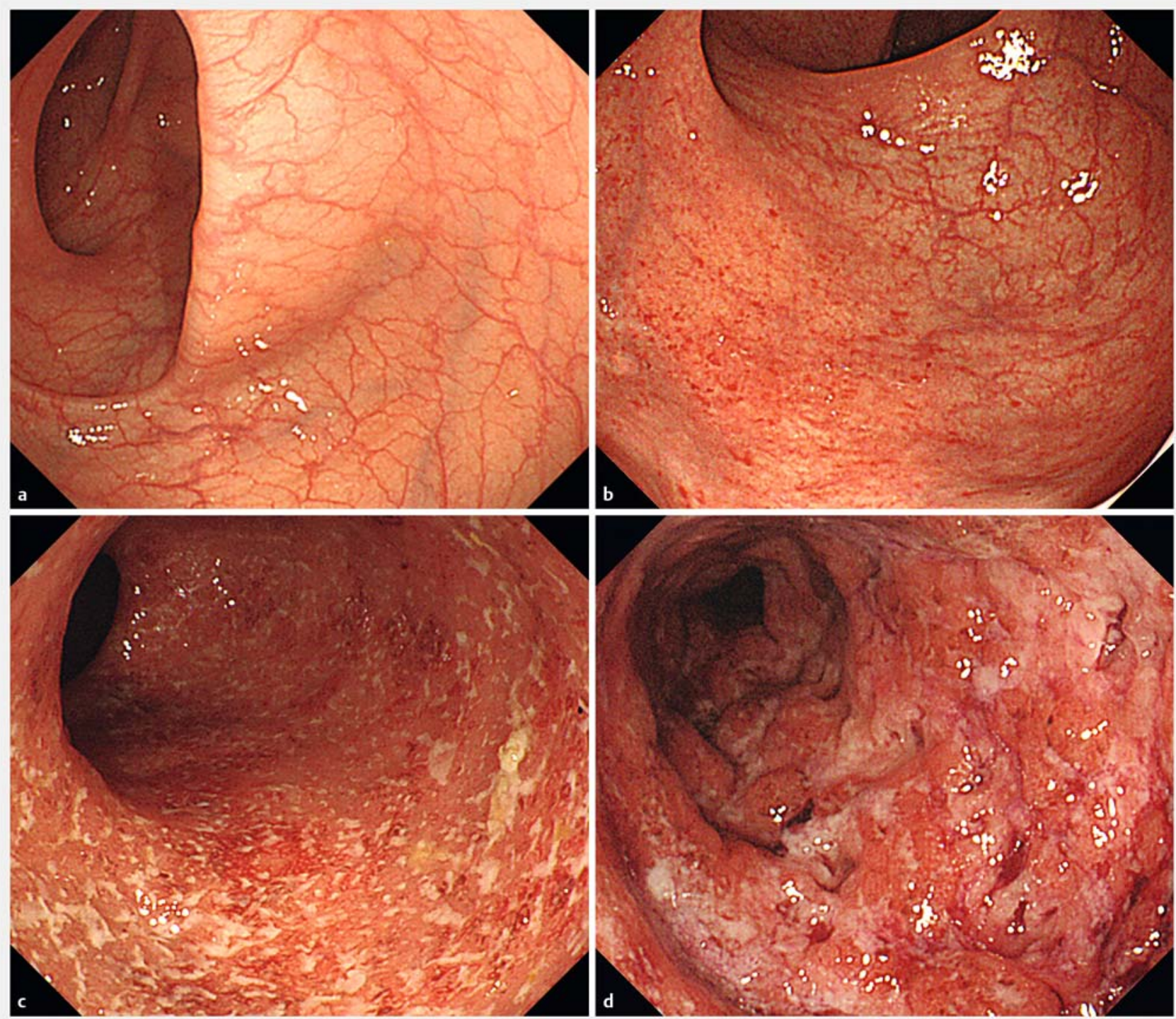

- Fig. 2 Endoscopic image of Mayo endoscopic subscore (MES). a Endoscopic image of MES 0 (no friability, granularity, and intact vascular pattern). b Endoscopic image of MES 1 (mild erythema or decreased vascular pattern). c Endoscopic image of MES 2 (marked erythema, absent vascular pattern, friability, and erosions). $\mathbf{d}$ Endoscopic image of MES 3 (spontaneous bleeding and ulceration).

of the findings, cases were scored by assigning one point each to the following three items: presence of redness, visible vascular pattern, and fine mucosal granularity. When the mean of scores calculated by the two endoscopists was two or higher, patients were determined to have MES 1 . To evaluate endoscopic findings, scores of the colon segments with the most severe inflammation were used.

\section{Histological evaluation}

Pathological examination was performed by a pathologist who specialized in pathology of gastrointestinal diseases. Severity of histological inflammation was graded as follows, according to the Matts classification [27]: 1, normal; 2, infiltration of round cells and polymorphonuclear leukocytes into the mucosa and lamina propria; 3 , moderate cell infiltration and partial infiltra- tion into the submucosa; 4, crypt abscess and marked cell infiltration of all mucosal layers; 5, erosion, ulceration, mucosal necrosis, and marked cell infiltration. Patients with Matts 1 and 2 were included in the histological healing $(\mathrm{HH})$ group, and those with Matts 3, 4, and 5, in the non-histological healing $(\mathrm{NHH})$ group.

\section{Statistical analyses}

Statistical analyses were performed with IBM SPSS Statistics 24 (IBM Japan, Ltd., Tokyo, Japan). The Cohen kappa coefficient (к) was calculated to determine the agreement rate between the two endoscopists who evaluated the endoscopic findings. The Pearson $x^{2}$ test was performed to compare sex, affected area, endoscopic classification, histological classification, smoking rate, and duration of remission before entry. When the expect- 
- Table 1 Background characteristics of the patients.

\begin{tabular}{|l|c|}
\hline Characteristics ( $\mathbf{n}=\mathbf{1 6 6})$ & \\
\hline Mean age (years) & $48.5 \pm 15.3$ \\
\hline Sex (male) & $51.2 \%(n=85)$ \\
\hline Affected area & \\
\hline - Proctitis type (E1) & $15.1 \%(n=25)$ \\
\hline - Left-sided type (E2) & $33.1 \%(n=55)$ \\
\hline - Pancolitis type (E3) & $51.8 \%(n=86)$ \\
\hline Endoscopic classification & \\
\hline - MES 0 & $54.8 \%(n=91)$ \\
\hline - MES 1 & $45.2 \%(n=75)$ \\
\hline Histological classification & $73.5 \%(n=122)$ \\
\hline - Matts 1,2(HH) & $26.5 \%(n=44)$ \\
\hline - Matts 3,4,5 (NHH) & $148.6 \pm 99.2$ \\
\hline Mean disease duration (months) & $44.8 \pm 25.5$ \\
\hline Mean duration of remission (months) & $3.0 \%(n=5)$ \\
\hline Smoking rate & \\
\hline $\begin{array}{l}\text { Values are presented as mean } \pm \text { standard deviation or } \%(n) . \\
\text { MES, Mayo endoscopic subscore; HH, histological healing; NHH, non-histo- } \\
\text { logical healing. }\end{array}$ \\
\hline
\end{tabular}

ed value was $<5$, the Fisher exact test was performed. The Mann-Whitney $U$ test was performed to compare mean age and mean disease duration. To compare the remission maintenance rate, survival curves were generated using the KaplanMeier method and the log-rank test was performed. The Cox proportional hazards model was used to identify predictors of clinical relapse. $P<0.05$ indicated statistical significance.

\section{Results}

\section{Analysis of study patients}

Background characteristics of the 166 study patients are shown in Table 1. According to the affected areas, proctitis type accounted for $15.1 \%$ of the patients $(n=25)$, left-sided type for $33.1 \%(n=55)$, and pancolitis type for $51.8 \%(n=86)$. Endoscopic findings were graded as MES 0 in $54.8 \%$ of the patients $(n=91)$ and MES 1 in $45.2 \%(n=75)$ ( $\vee$ Table 2$)$. Regarding the agreement rate of endoscopic evaluation between the two endoscopists, a high Cohen kappa coefficient $(\kappa=0.73)$ was obtained, indicating virtually complete agreement. Histological evaluation revealed $\mathrm{HH}$ in $73.5 \%(n=122)$ and $\mathrm{NHH}$ in $26.5 \%$ $(n=44)$ of the patients ( $\triangleright$ Table 3 ).

Of patients with MES 0, 91.2\% (83/91) achieved $\mathrm{HH}$, whereas $8.8 \%$ (8/91) had NHH. Meanwhile, $52.0 \%(39 / 75)$ of patients with MES 1 achieved $\mathrm{HH}$ and $48.0 \%(36 / 75)$ had $\mathrm{NHH}$.

\section{Mucosal healing and relapse-free survival}

When the MES 0 and MES 1 groups were compared and analyzed, the remission maintenance rate was higher in the MES 0 group, with a statistically significant difference (hazard ratio, 4.484; 95\% confidence interval, 1.474-13.642; $P=0.004$ ) ( Fig. 3).

\section{Histological healing and relapse-free survival}

The $\mathrm{HH}$ and $\mathrm{NHH}$ groups were compared and analyzed. The remission maintenance rate was higher in the $\mathrm{HH}$ group, with a statistically significant difference (hazard ratio, 3.866; $95 \%$ confidence interval, 1.497-9.982; $P=0.003$ ) ( $/$ Fig.4). Furthermore, when the $\mathrm{HH}$ and $\mathrm{NHH}$ subgroups within the MES 0 group were compared and analyzed, no significant difference was observed in the remission maintenance rate (hazard ratio, 0.042; 95\% confidence interval, $0.000-66635 ; P=0.502$ )

- Table 2 Comparison of patient characteristics between the MES 0 and MES 1 groups

\begin{tabular}{|c|c|c|c|}
\hline Characteristics $(n=166)$ & MES $0(n=91)$ & MES $1(n=75)$ & $P$ \\
\hline Mean age (years) & $50.1 \pm 15.9$ & $46.7 \pm 14.5$ & NS \\
\hline Sex (male) & $45.1 \%(n=41)$ & $58.7 \%(n=44)$ & NS \\
\hline Affected area & & & NS \\
\hline - Proctitis type (E1) & $15.4 \%(n=14)$ & $14.7 \%(n=11)$ & \\
\hline - Left-sided type (E2) & $36.3 \%(n=33)$ & $29.3 \%(n=22)$ & \\
\hline - Pancolitis type (E3) & $48.4 \%(n=44)$ & $56.0 \%(n=42)$ & \\
\hline \multicolumn{4}{|l|}{ Histological classification } \\
\hline - Matts 1,2(HH) & $91.2 \%(n=83)$ & $52.0 \%(n=39)$ & NS \\
\hline - Matts 3,4,5(NHH) & $8.8 \%(n=8)$ & $48.0 \%(n=36)$ & NS \\
\hline Mean disease duration (months) & $140.4 \pm 84.1$ & $158.4 \pm 114.8$ & NS \\
\hline Smoking rate & $2.2 \%(n=2)$ & $4.0 \%(n=3)$ & NS \\
\hline
\end{tabular}


- Table 3 Comparison of patient characteristics between the HH and NHH groups.

\begin{tabular}{|c|c|c|c|}
\hline Characteristics $(n=166)$ & HH group $(n=122)$ & NHH group $(n=44)$ & $P$ \\
\hline Mean age (years) & $48.7 \pm 15.2$ & $48.0 \pm 15.9$ & NS \\
\hline Sex (male) & $49.2 \%(n=60)$ & $56.8 \%(n=25)$ & NS \\
\hline Affected area & & & NS \\
\hline - Proctitis type (E1) & $15.6 \%(n=19)$ & $13.6 \%(n=6)$ & \\
\hline - Left-sided type (E2) & $34.4 \%(n=42)$ & $29.6 \%(n=13)$ & \\
\hline - Pancolitis type (E3) & $50.0 \%(n=61)$ & $56.8 \%(n=25)$ & \\
\hline \multicolumn{4}{|l|}{ Endoscopic classification } \\
\hline - MES 0 & $68.0 \%(n=83)$ & $18.2 \%(n=8)$ & NS \\
\hline - MES 1 & $32.0 \%(n=39)$ & $81.8 \%(n=36)$ & NS \\
\hline Mean disease duration (months) & $146.3 \pm 102.3$ & $154.9 \pm 91.1$ & NS \\
\hline Smoking rate & $2.4 \%(n=3)$ & $4.5 \%(n=2)$ & NS \\
\hline
\end{tabular}

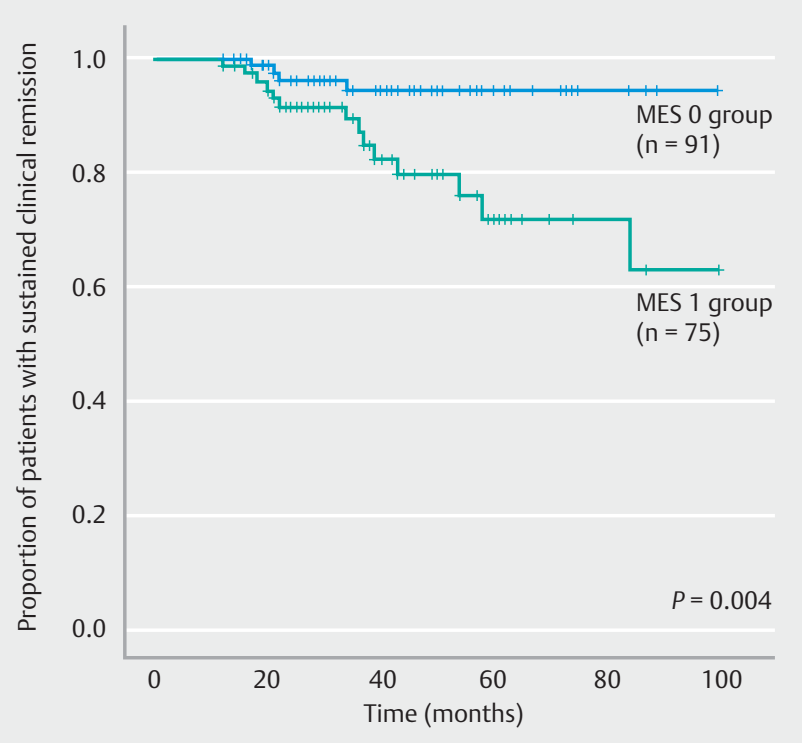

- Fig. 3 Comparison of remission maintenance rates between the MES 0 and MES 1 groups. MES, Mayo endoscopic subscore.

( $>$ Fig.5). Moreover, when the $\mathrm{HH}$ and $\mathrm{NHH}$ subgroups within the MES 1 group were compared and analyzed, the remission maintenance rate was higher in the $\mathrm{HH}$ subgroup, with a statistically significant difference (hazard ratio, 3.744; 95\% confidence interval, 1.041-13.466; $P=0.030$ ) ( Fig. 6). Meanwhile, comparison of the $\mathrm{HH}$ subgroups of the MES 0 and MES 1 groups did not reveal any significant difference in the remission maintenance rate (hazard ratio, 1.640; $95 \%$ confidence interval, $0.367-7.337 ; P=0.512$ ) ( Fig. 7).

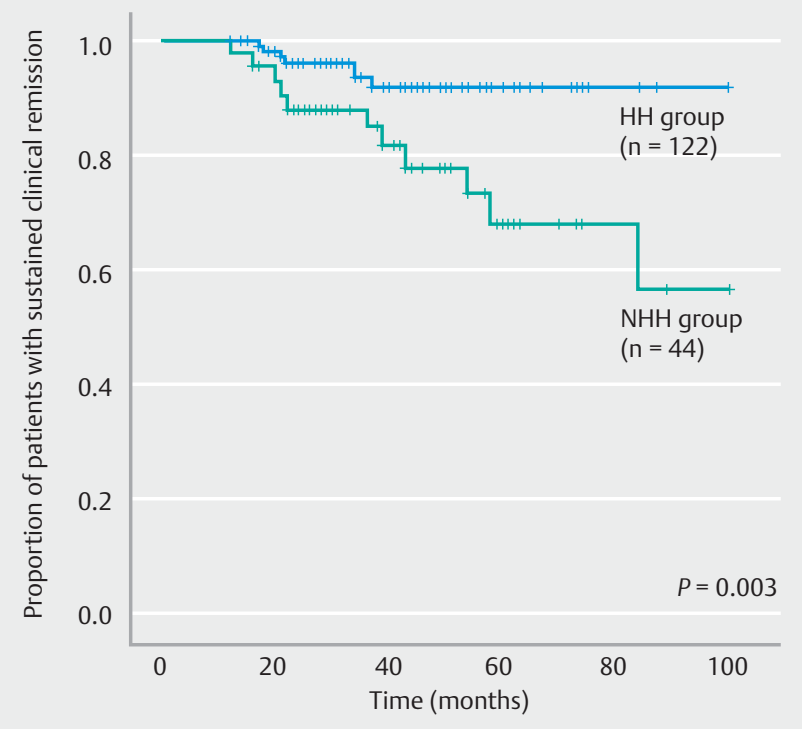

Fig. 4 Comparison of remission maintenance rates between the $\mathrm{HH}$ and $\mathrm{NHH}$ groups. $\mathrm{HH}$, histological healing; $\mathrm{NHH}$, non-histological healing.

\section{Risk factors}

Age, sex, affected area, disease duration, smoking rate, and duration of remission before entry were analyzed, but none was identified to be a significant factor for predicting presence or absence of relapse ( $\triangleright$ Table 4$)$.

\section{Discussion}

The International Organization for the Study of Inflammatory Bowel Disease defines MH as "an absence of friability, bleeding, erosions, or ulcerations in all endoscopically observable seg- 


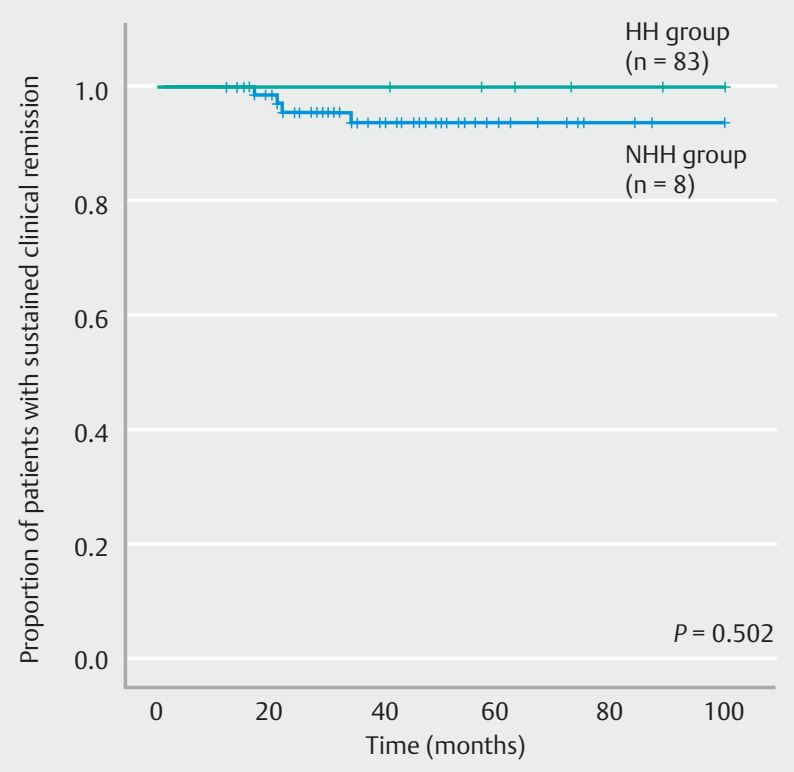

- Fig. 5 Comparison of remission maintenance rates between the $\mathrm{HH}$ and $\mathrm{NHH}$ subgroups within the MES 0 group. $\mathrm{HH}$, histological healing; $\mathrm{NHH}$, non-histological healing; MES, Mayo endoscopic subscore.

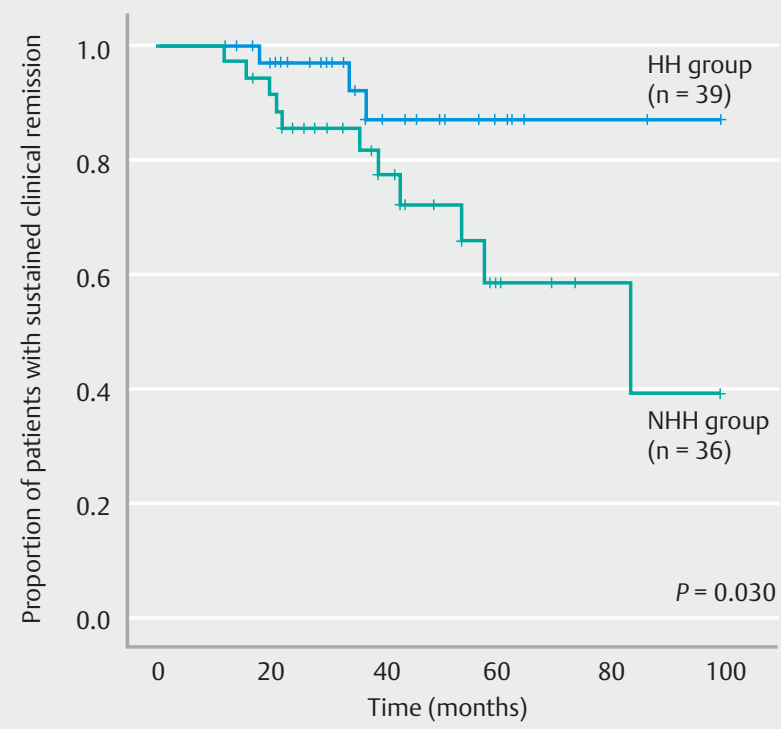

- Fig. 6 Comparison of remission maintenance rates between the $\mathrm{HH}$ and $\mathrm{NHH}$ subgroups within the MES 1 group. $\mathrm{HH}$, histological healing; $\mathrm{NHH}$, non-histological healing; MES, Mayo endoscopic subscore.

ments of the intestinal mucosa" [2]. Based on previous studies, the remission maintenance rate is high in patients achieving $\mathrm{MH}$ [3-14]. MES and Matts classification have never been fully validated, but do represent two of the most widely used scores to quantify endoscopic and histologic activity, respectively. MES is widely used to evaluate the mucosa, and MES 0 and

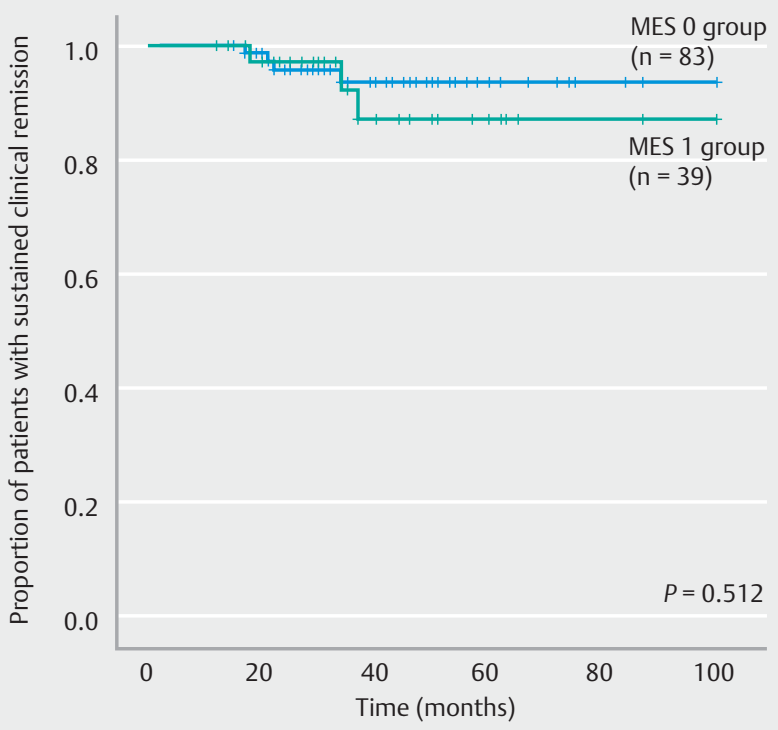

Fig. 7 Comparison of the remission maintenance rates between the MES 0 and MES 1 subgroups within the HH group. MES, Mayo endoscopic subscore; $\mathrm{HH}$, histological healing.

MES 1 correspond to endoscopic MH [6]. However, no consistent views have been reached on whether the remission maintenance rate differs between patients with MES 0 and MES 1 [7, $10,28]$. The current study revealed a higher remission maintenance rate in the MES 0 group than in the MES 1 group, indicating that if the mucosal condition is endoscopically confirmed as MES 0, probability of relapse can be expected to be low. Meanwhile, approximately $30 \%$ of patients with MES 1 experienced relapse in 60 months. Even in patients with endoscopically confirmed $\mathrm{MH}$, estimating the probability of relapse separately in those with MES 0 and MES 1 seemed necessary.

In recent years, histological healing has been considered to be a much superior indicator of remission maintenance to $\mathrm{MH}$. It has also been suggested that not only $\mathrm{MH}$ but also resolution of histological inflammation is associated with decreases in relapse rate, hospitalization rate, steroid use, surgery rate, and risk of UC-associated colorectal cancer [4, 15-20,29-33]. Riley et al. demonstrated in a study of 82 UC patients that the rate of relapse within 12 months was significantly higher in patients with histological findings of acute inflammatory cell infiltration, crypt abscess, and goblet cell depletion [15]. Bitton et al. reported in a study of 74 UC patients in clinical and endoscopic remission that presence of basal plasmacytosis detected by rectal biopsy is an independent predictor of relapse of UC [17]. Bryant et al. reported that, compared with endoscopic $\mathrm{MH}$, histological healing is more useful for predicting development of severe acute colitis requiring remission induction with corticosteroids or hospitalization [19]. Feagins et al. studied histological findings from 51 UC patients in clinical remission and reported that presence of basal lymphoplasmacytic tumor, epithelial erosion/ulceration, and moderate to severe structural changes is significantly useful for predicting clinical relapse at 6 
- Table 4 Analysis of risk factors for relapse.

\begin{tabular}{|c|c|c|}
\hline Risk factor & Hazard ratio $(95 \% \mathrm{Cl})$ & $P$ value \\
\hline Age & $0.988(0.956-1.021)$ & 0.455 \\
\hline Sex (male) & $1.056(0.397-2.808)$ & 0.914 \\
\hline Affected area & & NS \\
\hline - Proctitis type (E1) & - & 0.811 \\
\hline - Left-sided type (E2) & $0.744(0.150-3.690)$ & 0.717 \\
\hline - Pancolitis type (E3) & $1.248(0.436-3.571)$ & 0.680 \\
\hline Disease duration & $1.000(0.996-1.005)$ & 0.876 \\
\hline Smoking rate & - & 0.999 \\
\hline MES0 vs MES1 & $4.484(1.474-13.642)$ & 0.004 \\
\hline $\mathrm{HH}$ vs $\mathrm{NHH}$ & $3.866(1.497-9.982)$ & 0.003 \\
\hline MESO (HH vs NHH) & $0.042(0.000-66635)$ & 0.502 \\
\hline MES1 (HH vs NHH) & $3.744(1.041-13.466)$ & 0.030 \\
\hline HH (MES0 vs MES1) & $1.640(0.367-7.337)$ & 0.512 \\
\hline Duration of remission before entry & $1.110(0.414-2.973)$ & 0.836 \\
\hline
\end{tabular}

and 12 months. Compared with assessment of only endoscopic findings, assessment of histological findings was reported to be more useful for predicting relapse [20]. Christensen et al. reported that histological healing can be used as a clinical endpoint for UC patients and that histological evaluation should be a part of endoscopic evaluation as an indicator of activity of IBD [33].

We investigated the importance of assessing histological healing in patients who had remained in clinical remission for a long time and had been found to have $\mathrm{MH}$ by colonoscopy. Our study yielded results comparable to those of previous studies. Within the MES 1 group, the HH subgroup showed a higher remission maintenance rate than the NHH subgroup. Meanwhile, within the $\mathrm{HH}$ group, the remission maintenance rates were comparable between the MES 0 and MES 1 subgroups. These results indicated that if histological inflammation is graded as Matts 1 or 2 in patients with MES 1, their remission maintenance rate is comparable with that in patients with MES 0 .

In the current study, risk factors for relapse of UC were also investigated through analyses of secondary endpoints. On this issue, various studies have been conducted. Bitton et al. reported that early relapse is associated with younger age, short duration of remission before their investigation, and frequency of prior relapses [17]. Meanwhile, Christensen et al. reported that age, sex, smoking, disease duration, and affected area did not show any significant difference as factors for remission maintenance [33]. No consistent views have been reached. The current study analyzed age, sex, affected area, disease duration, smoking rate, and duration of remission before entry, but none was a significant risk factor for relapse. However, because the current study was retrospective, lifestyle habits were not rigorously assessed. We hope that future prospective studies may provide new findings.

As for the limitations of the current study, we did not assess effects of remission induction techniques (use of steroids, tacrolimus, biological drugs, etc.), doses and types of 5-ASA preparations, application of topical drugs, or lack of details on maintenance treatments for patients in endoscopic/histologic remission.

Another limitation was the retrospective study design. However, because no other study has been conducted on patients in sustained remission, our study presumably provided an indicator for predicting relapse in such patients.

\section{Conclusion}

In conclusion, although MES 0 and MES 1 are often regarded as corresponding to $\mathrm{MH}$, this study suggests that histological healing could be a predictor of sustained remission in UC patients. Particularly in patients with MES 1, examination of histological inflammation seemed useful for long-term management of UC. To apply the results of the current study to clinical practice, we recommend that well-designed multicenter prospective studies be conducted. Furthermore, we believe that it would be better to design similar research in Crohn's disease in the future.

\section{Competing interests}

None 


\section{References}

[1] Kornbluth A, Sachar DB. Practice Parameters Committee of the American College of Gastroenterology. Ulcerative colitis practice guidelines in adults: American College of Gastroenterology, Practice Parameters Committee. Am J Gastroenterol 2010; 105: 501- 523

[2] D'Haens G, Sandborn WJ, Feagan BG et al. A review of activity indices and efficacy end points for clinical trials of medical therapy in adults with ulcerative colitis. Gastroenterology 2007; 132: 763-786

[3] Froslie KF, Jahnsen J, Moum BA et al. Mucosal healing in inflammatory bowel disease: results from a Norwegian population-based cohort. Gastroenterology 2007; 133: 412-422

[4] Truelove SC, Richards WC. Biopsy studies in ulcerative colitis. Br Med ] 1956; $1: 1315-1318$

[5] Neurath MF, Travis SP. Mucosal healing in inflammatory bowel diseases: a systematic review. Gut 2012; 61: 1619-1635

[6] Colombel JF, Rutgeers P, Reinisch W et al. Early mucosal healing with infliximab is associated with improved longterm clinical outcomes in ulcerative colitis. Gastroenterology 2011; 141: 1194-1201

[7] Meucci G, Fasoli R, Saibeni S et al. Prognostic significance of endoscopic remission in patients with active ulcerative colitis treated with oral and topical mesalazine: a prospective, multicenter study. Inflamm Bowel Dis 2012; 18: 1006 - 1010

[8] Ardizzone S, Andrea C, Piergiorgio D et al. Mucosal healing predicts late outcomes after the first course of corticosteroids for newly diagnosed ulcerative colitis. Clin Gastroenterol Hepatol 2011; 9: 483-489

[9] Gibson PR, Vaizey C, Black CM et al. Relationship between disease severity and quality of life and assessment of health care utilization and cost for ulcerative colitis in Australia: a cross-sectional, observational study. J Crohns Colitis 2014; 8: 598-606

[10] Takahashi F, Tominaga K, Kanamori A et al. Timing for dose-down of 5-ASA depends on mucosal status with ulcerative colitis. Scand J Gastroenterol 2016; 51: 827-834

[11] Sandborn W], Rutgeerts P, Feagan BG et al. Colectomy rate comparison after treatment of ulcerative colitis with placebo or infliximab. Gastroenterology 2009; 137: 1250 - 1260

[12] Feagan BG, Reinisch W, Rutgeerts P et al. The effects of infliximab therapy on health-related quality of life in ulcerative colitis patients. Am J Gastroenterol 2007; 102: 794 - 802

[13] Peyrin-Biroulet L, Sandborn W, Sands BE et al. Selecting therapeutic targets in inflammatory bowel disease (STRIDE): determining therapeutic goals for treat-to-target. Am J Gastroenterol 2015; 110: $1324-1338$

[14] Boal Carvalho P, Cotter J. Mucosal healing in ulcerative colitis: a comprehensive review. Drugs 2017; 77: 159-173

[15] Riley SA, Mani V, Goodman MJ et al. Microscopic activity in ulcerative colitis: what does it mean? Gut 1991; 32: 174-178

[16] Bessissow T, Lemmens B, Ferrante $M$ et al. Prognostic value of serologic and histologic markers on clinical relapse in ulcerative colitis patients with mucosal healing. Am J Gastroenterol 2012; 107: 1684 1692

[17] Bitton A, Peppercorn MA, Antonioli DA et al. Clinical, biological, and histologic parameters as predictors of relapse in ulcerative colitis. Gastroenterology 2001; 120: 13-20
[18] Park S, Abdi T, Gentry M et al. Histological disease activity as a predictor of clinical relapse among patients with ulcerative colitis: systematic review and meta-analysis. Am J Gastroenterol 2016; 111: $1692-1701$

[19] Bryant RV, Burger DC, Delo J et al. Beyond endoscopic mucosal healing in UC: histological remission better predicts corticosteroid use and hospitalisation over 6 years of follow-up. Gut 2016; 65: 408 - 414

[20] Feagins LA, Melton SD, Iqbal R et al. Clinical implications of histologic abnormalities in colonic biopsy specimens from patients with ulcerative colitis in clinical remission. Inflamm Bowel Dis 2013; 19: 1477 1482

[21] Rachmilewitz D. Coated mesalazine (5-aminosalicylic acid) versus sulphasalazine in the treatment of active ulcerative colitis: a randomised trial. BM] 1989; 298: 82-86

[22] Matsuoka K, Kobayashi T, Ueno F et al. Evidence-based clinical practice guidelines for inflammatory bowel disease. J Gastroenterol 2018; 53: $305-353$

[23] Silverberg MS, Satsangi J, Ahmad T et al. Toward an integrated clinical, molecular and serological classification of inflammatory bowel disease: report of a Working Party of the 2005 Montreal World Congress of Gastroenterology. Can J Gastroenterol 2005; 19: 5A-36A

[24] Satsangi J, Silverberg MS, Vermeire $S$ et al. The Montreal classification of inflammatory bowel disease: controversies, consensus, and implications. Gut 2006; 55: 749-753

[25] Schroeder KW, Tremaine W], Ilstrup DM. Coated oral 5-aminosalicylic acid therapy for mildly to moderately active ulcerative colitis. A randomized study. N Engl J Med 1987; 317: 1625 - 1629

[26] Scherl E], Pruitt R, Gordon GL et al. Safety and efficacy of a new $3.3 \mathrm{~g}$ b.i.d. tablet formulation in patients with mild-to-moderately-active ulcerative colitis: a multicenter, randomized, double-blind, placebocontrolled study. Am J Gastroenterol 2009; 104: 1452 - 1459

[27] Matts SG. The value of rectal biopsy in the diagnosis of ulcerative colitis. Q J Med 1961; 30: $393-407$

[28] Nakarai A, Kato J, Hiraoka S et al. Prognosis of ulcerative colitis differs between patients with complete and partial mucosal healing, which can be predicted from the platelet count. World J Gastroenterol 2014; 20: $18367-18374$

[29] Rubin DT, Huo D, Kinnucan JA et al. Inflammation is an independent risk factor for colonic neoplasia in patients with ulcerative colitis: a case-control study. Clin Gastroenterol Hepatol 2013; 11: 1601-1608

[30] Gupta RB, Harpaz N, Itzkowitz S et al. Histologic inflammation is a risk factor for progression to colorectal neoplasia in ulcerative colitis: a cohort study. Gastroenterology 2007; 133: 1099-1105

[31] Hefti MM, Chessin DB, Harpaz NH et al. Severity of inflammation as a predictor of colectomy in patients with chronic ulcerative colitis. Dis Colon Rectum 2009; 52: $193-197$

[32] Peyrin-Biroulet L, Bressenot A, Kampman W. Histologic remission: the ultimate therapeutic goal in ulcerative colitis? Clin Gastroenterol Hepatol 2014; 12: 929-934

[33] Christensen B, Hanauer SB, Erlich J et al. Histologic normalization occurs in ulcerative colitis and is associated with improved clinical outcomes. Clin Gastroenterol Hepatol 2017; 15: 1557 -1564 